\title{
Does Style of Thinking Make Differences in Consumer Judgments on Brand Extensions?
}

\author{
Shin-Shin Chang \\ Chung Yuan Christian University \\ E-Mail: edelweissaa9@gmail.com
}

\begin{abstract}
Category similarity and benefit similarity have been identified as two important factors that determine a brand extension's success. However, which of these two factors has a greater impact on consumers' evaluations has received little attention. This study posits that the relative advantages are moderated by people's style of thinking - holistic versus analytic. Specifically, analytic (holistic) thinkers have more favorable evaluations about benefit-similarity (category-similarity) extensions than category-similarity (benefit-similarity) extensions. Results from an experimental design supported this proposed hypotheses.
\end{abstract}

Keywords: Style of Thinking, Culture, Brand Extension, Benefit Similarity, Category Similarity

\section{INTRODUCTION}

Prior research has found that people's perceptions, categorizations, and causal attributions vary among different cultures. As a consequence of socialization, a style of thinking that is reflective of differences between East Asians and Westerners may emerge (Nisbett, Peng, Choi, \& Norenzayan, 2001). Westerners are usually more concerned about the target object itself rather than the context, which is an analytic thinking style, whereas Easterners are inclined to observe the phenomenon between objects and the context, which is a holistic thinking style. Style of thinking has many practical implications in areas such as advertising, attraction effects, and negative brand publicity (Liang, 2012; Mao \& Oppewal, 2012; Monga \& John, 2008)

Brand extension is an important strategy that marketers frequently employ to broaden their offerings in the marketplace. Consumers' favorable evaluations can be affected by a number of factors. Key among these is the perceived fit between an extension and its parent brand (Mandler, 1982). A higher perceived fit gives rise to 
more favorable evaluations from consumers (Keller\& Aaker, 1992). This perceived fit can result from a variety of factors, such as whether the extension and the parent brand are within the same product category, whether they are associated with the same product benefits (Meyvis \& Janiszewski, 2004; Chang, Lin, \& Chang, 2011), and the transferability of the parent brand's reputation or image of prestige (Boush \& Loken, 1991; Monga \& John, 2007; Yeo \& Park, 2006).

Recent studies have shown that the effect of perceived fit on consumer evaluations may be moderated by individuals' goal orientation. Specifically, the relative impacts of category-similar and benefit-similar extensions on consumer attitudes have been shown to be contingent upon people's motivational orientation: promotion-focus or prevention-focus. Because promotion-focused individuals tend to maximize benefits, they evaluate a benefit-similar extension more favorably, as it ensures the anticipated benefits. On the contrary, prevention-focused individuals are more concerned with minimization of risks and are therefore more favorable to a category-similar extension, as it is associated with fewer risks (Chang et al., 2011; Chernev, 2004; Zhou \& Pham, 2004).

To date, very little attention has been devoted to investigate whether past findings in the field of brand extensions are applicable to people from different cultures. This issue is especially important to global companies, as they frequently implement brand extension strategies around the world. It is plausible to conjecture that people from various cultures may judge the perceived extension fit in different ways. For instance, it was found that U.S. customers are more concerned with brand extension fit than customers in Hong Kong (Han \& Schmitt, 1997).

Monga and John (2007) have been pioneers in exploring whether cultural differences lead to different ways of judging the brand extension fit, which results in different brand evaluations. In particular, they claim that a style of thinking may affect perceived extension fit. Two different styles of thinking have been proposed by Nisbett, Peng, Choi, and Norenzayan (2001). Compared to analytic thinkers, holistic thinkers are found to categorize objects based on category membership or attributes (Chiu, 1972), to focus greater attention on relationships between an object and its context ( $\mathrm{Ji}$, Peng, \& Nisbett, 2000), and to engage more heavily in rule-based categorization (Norenzayan, Smith, Kim, \& Nisbett, 2002). Regarding people's evaluations of a brand extension, holistic thinkers have more favorable attitudes toward distant extensions than analytic thinkers for functional parent brands, whereas holistic and analytic thinkers share equal attitudes toward a distant extension from prestigious parent brands (Monga \& John, 2010). 
Chiu (1972) demonstrated that analytic thinkers grouped a jeep and a boat together because both had motors (benefit similarity), and holistic thinkers grouped a table and a chair together because people sit on the chair to eat at the table (product category similarity). Since a holistic thinker tends to focus on the relationships between a focal object and the context, while an analytic thinker is inclined to focus on the attributes of a focal object to assign categories, will a holistic (analytic) thinker evaluate a category-similar (benefit-similar) extension more favorably than a benefit-similar (category-similar) extension? In summary, it seems plausible to predict that styles of thinking will influence the relative impacts of individuals' evaluations of category-similar and benefit-similar brand extensions.

This research aims to investigate whether the thinking style of consumers plays a crucial role in brand extension evaluations. A relevant question that arises is as follows: What is the underlying cause of the divergence in assessing brand extension strategy between distinct cultures? In the following sections, we first begin by providing an overview of brand extensions, and the draw attention to the effects of people's styles of thinking in constructing underlying mechanisms. We then conduct an experiment to examine the propositions. Finally, conclusions and implications are discussed and reported.

\section{CONCEPTUAL FRAMEWORK}

\section{Brand Extensions: Category Similarity and Benefit Similarity}

To the extent that successful brand extensions are associated with several elements, in this research, we aim particularly at introducing two of these elements: product category similarity and core benefit similarity.

\section{Parent-Extension Similarity and Extension Evaluations}

Consumers tend to judge similarities between an extension and its parent brand. One way to judge these similarities is to examine whether the extension and the parent brand are in a similar product class or category. Consumers are prone to predict the possible performance of the extension based on their existing evaluations of the parent brand. If an extension is in a product category that is similar to those associated with the parent brand, the image of the parent brand can be easily generalized to the extension (Boush \& Loken, 1991; Chakravarti, MacInnis, \& Nakamoto, 1990). An extension in a dissimilar product category may induce a sense of incongruity, and a greater perceived risk arises accordingly (Campbell $\&$ Goodstein, 2001). Another method of assessing the similarities between the extension and the parent brand is to investigate whether they provide similar core benefits (Dacin \& Smith, 1994). Consumers who are more concerned with the benefits they obtain from using the 
extension may prefer an extension offering the same benefits as the parent brand due to their expectation that the parent brand's ability to successfully ensure a provision of a certain benefit should be competent to offer the same benefit once again in the extension. Meyvis and Janiszewski (2004) demonstrated that extensions from a broad brand whose products have weak and diffuse category associations may prompt more favorable attitudes than those of a narrow brand if consumers can access core benefits shared with other successful categories. In sum, a category-similar extension strategy minimizes consumers' perceived risks, whereas a benefit-similar extension strategy strives to maximize consumers' anticipated gains.

\section{Style of Thinking}

People's cognitive differences can be grouped under the headings of analytic and holistic thought (Peng \& Nisbett, 1999; Nisbett, 1998; Nisbett et al., 2001). Holistic thinkers are characterized by their orientation to the context as a whole. They are prone to focus on the relationships between a focal object and its context, are inclined to use these relationships to make inferences and provide explanations, and are generally reliant upon experience-based knowledge. On the contrary, analytic thinkers often detach an object from its context, tend to focus on the attributes of the object that assign it to a specific category, and rely on abstract logic and rule-based knowledge to make judgments. Thereby, they generally engage more in rule-based categorization (John, 2004; Norenzayan et al., 2002). Most empirical research to date has shown that holistic thinkers, when compared to analytic thinkers, are inclined to categorize objects by category membership or attributes (Chiu, 1972) and pay attention to relationships between an object and its context (Ji et al., 2000). More recent research has posited that individuals' styles of thinking can affect their evaluations about distant extensions from the parent brand (Monga \& John, 2007; Ahluwalia, 2008) and has demonstrated that holistic thinkers evaluate distant extensions more favorably than analytic thinkers regarding when the parent brand is of a functional brand concept, whereas both holistic and analytic thinkers demonstrate equal attitudes toward distant extensions when the parent brand is of a prestigious brand concept (Monga \& John, 2010). For analytic thinkers, a distant extension implies a different product category and different function, which makes it difficult for them to perceive the extension from the parent brand, thereby evaluating this distant extension unfavorably. Holistic thinkers, on the contrary, focus on the context rather than the object (Choi, Nisbett, \& Norenzayan, 1999), suggesting complementary use and the overall parent brand image as the basis for a fit between an extension and its parent brand (Monga \& John, 2010). Additionally, holistic thinkers are found to demonstrate a stronger association between events (Ji et al, 2000), 
which implies that they could perceive a fit between a distant extension and the parent brand simply because they are marketed under the same brand name.

\section{HYPOTHESES: JOINT INFLUENCES OF STYLE OF THINKING AND TYPES OF BRAND EXTENSIONS}

It is proposed that both category similarity and benefit similarity lead to greater brand extension success, but the style of thinking of consumers may moderate these impacts on the evaluations of brand extensions.

Because analytic thinkers tend to detach an object from its context and to base their inferences and judgments on attributes of objects as well as rule-based knowledge, this makes it difficult for them to perceive fits between extensions in a similar product category that offer different core benefits than their parent brand. However, when evaluating extensions that share a similar core benefit with the parent brand although they are in a different category, perceived fits could arise because shared core benefits provide a plausible criterion to infer the quality and performance of extensions from parent brand images.

To the contrary, holistic thinkers have a strong tendency to focus on the relationship between the focal object and its context (Choi et al., 1999) and to pay more attention to broader connections (Masuda \& Nisbett, 2001). They are prone to base their inference and judgment on experience-based knowledge. Because the similarity of product category between extensions and the parent brand could be regarded as an excellent contextual factor, thus representing plausible connections or relationships, this lead holistic thinkers to favorably evaluate the extensions.

To summarize, an extension of similar category but a dissimilar benefit with the parent brand gives rise to a perceived fit for holistic thinkers, whereas an extension of similar core benefit but a dissimilar category with the parent brand results in a perceived fit for analytic thinkers. Hence, the hypotheses and the conceptual model (see figure 1) are proposed as follows.

H1: Analytic thinkers have more favorable evaluations of benefit-similar brand extensions than category-similar brand extensions.

H2: Holistic thinkers have more favorable evaluations of category-similar brand extensions than benefit-similar brand extensions. 


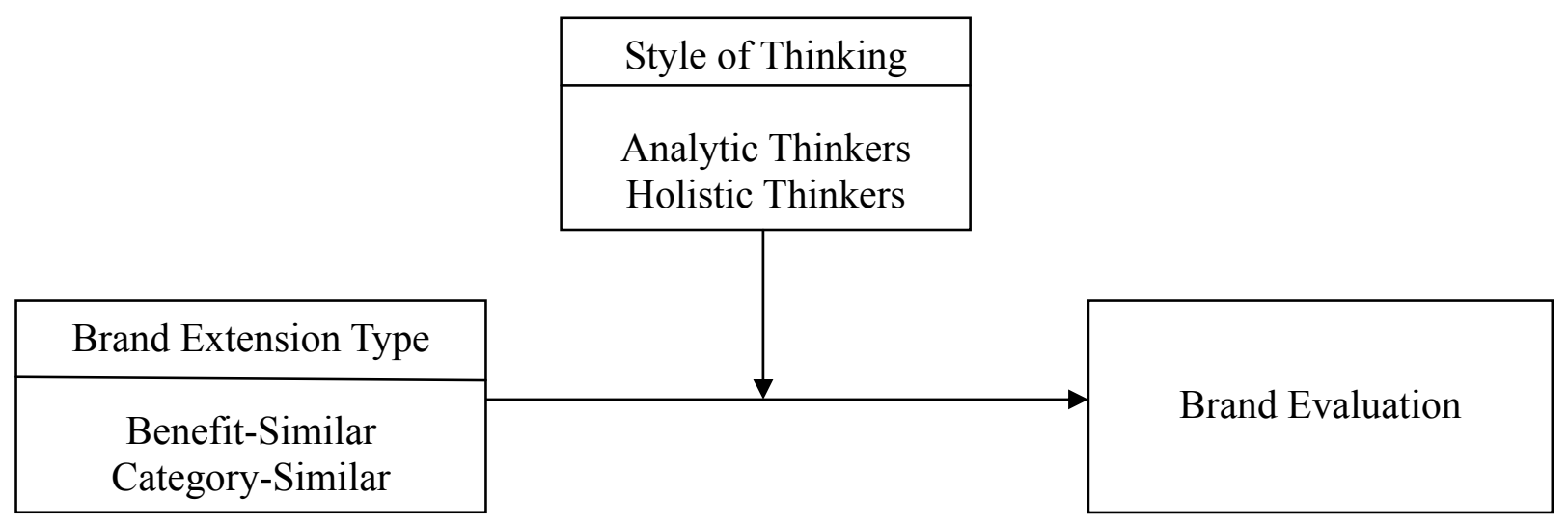

Figure 1 Conceptual Model

\section{EXPERIMENT}

\section{Method}

- Participants and design

The hypotheses were tested in a 2 (style of thinking: analytic vs. holistic) $\times 2$ (category-similar vs. benefit-similar) experimental design. There were 128 participants $(55 \mathrm{male}$, Mage $=22.33$ years, $\mathrm{SDage}=3.23 ; 73$ female, Mage $=22.14$, SDage $=3.32)$ in this study. Holistic and analytic thinkers were identified using statements from the analytic-holistic scale, which was developed by Choi, Koo, and Choi (2007): "The whole, rather than parts, should be considered in order to understand a phenomenon;" "It is more important to pay attention to the whole than its parts;" "The whole is greater than the sum of its parts;" "It is more important to pay attention to the whole context rather the details;" and "It is not possible to understand the parts without considering the whole picture." Participants were asked to agree or disagree $(1=$ "strongly disagree," and 7 = "strongly agree") with each statement. Their responses are averaged to arrive at a score for each respondent. A median split $(\mathrm{M}=4.0)$ was used to classify them into analytic or holistic thinkers. Participants with scores higher than the median split are identified as holistic thinkers, while those with scores lower than the median split are identified as analytic thinkers.

- Stimuli and procedure

After providing answers pertaining to the analytic-holistic thinking scale, participants were instructed to read descriptions of a fictional electrical appliance brand, "Skyline," which has marketed electric shavers for years and has earned a strong 
reputation as a bathroom product with high quality of blades. For the brand extension manipulation, participants in the category-similar (benefit-similar) condition were told that recently, Skyline launched an electric toothbrush (category-similar extension) or a food processor (benefit- similar extension) with the brand name of Skyline in the marketplace. They were then asked to provide an evaluation regarding the extensions of electric toothbrushes and food processors. Participants were also required to provide data pertaining to demographics (i.e., gender, age, and income).

\section{Measures}

In line with the objectives of this study, participants were randomly assigned to one of two brand extension conditions, and they were then asked to answer three-item value expressive questions regarding Skyline electric toothbrushes (food processors) based on a seven-point Likert scale (agree/disagree): (1) "The functions and quality of Skyline's electric toothbrush (food processor) are good;" (2) "Skyline's electric toothbrush (food processor) is a good value for the price," and (3) "I would recommend Skyline's electric toothbrush (food processor) to my friends." Their answers to these three questions were then averaged.

For each extension in the two experimental conditions, a manipulation check question was administered on a seven-point Likert scale: Is the extension (electric toothbrush or food processor) similar to the electric shaver in reference to the product category or benefit provided? Participants were told to indicate a 7 if they strongly believe that the extension product is similar to the electric shaver in product category and to indicate a 1 if they strongly believe that the extension provides similar benefits to the electric shaver.

\section{Results}

- Reliability analysis

The Cronbach's $\alpha$ was 0.934 for the analytic-holistic scale and was 0.896 for the three statements used to evaluate brand extensions.

Manipulation checks

The average score of the manipulation check item for participants in the category-similar condition was 5.48 and 3.22 for those in the benefit- similar condition $(p<.000)$, which indicated the success of manipulation.

- Test of hypotheses

A two-way ANOVA was employed to examine how participants evaluate these two types of brand extensions differently. The results are shown in Table 1. 
Table 1 Effects of Thinking Style on Brand Extension Type on Extension Evaluation

\begin{tabular}{ccccc}
\hline $\begin{array}{c}\text { Type III Sum of } \\
\text { Squares }\end{array}$ & $d f$ & Mean Square & $F$ & Sig. \\
\hline $168.364^{\mathrm{a}}$ & 3 & 56.121 & 157.524 & .000 \\
2349.247 & 1 & 2349.247 & 6593.976 & .000 \\
1.563 & 1 & 1.563 & 4.386 & .038 \\
.075 & 1 & .075 & .210 & .647 \\
166.206 & 1 & 166.206 & 466.514 & .000 \\
44.178 & 124 & .356 & & \\
2581.556 & 128 & & &
\end{tabular}

Table 1 shows that there is a significant interaction effect between style of thinking and brand extension type $(F(1,124)=466.514, p<.000)$. A simple main effect analysis shows that analytical thinkers demonstrate a more favorable evaluation of benefit-similar extension than category-similar extension $(M=5.29$ vs. 3.06, $F(1,64)=189.123, \mathrm{p}<.000$ ) (see Table 2 and Figure 2). Holistic thinkers demonstrate a more favorable evaluation of category-similar extension than benefit-similar extension $(M=5.56$ vs. $3.23, F(1,60)=308.206, p<.00)$ (see Table 2 and Figure 2). Hence, hypothesis $\mathrm{H} 2$ is supported.

Table 2 Brand Evaluation as a Function of Style of Thinking and Brand Extension Types

\begin{tabular}{ccccc}
\hline \multicolumn{3}{c}{ Analytic Thinking } & \multicolumn{2}{c}{ Holistic Thinking } \\
\hline & Benefit-similar & Category-similar & Benefit-similar & Category-similar \\
& Extension & Extension & Extension & Extension \\
Brand & $5.29(0.78)$ & $3.06(0.51)$ & $3.23(0.58)$ & $5.56(0.46)$ \\
Evaluation & {$[n=33]$} & {$[n=33]$} & {$[n=30]$} & {$[n=32]$} \\
\hline \multicolumn{2}{l}{ Note: The standard deviation is shown in the parentheses. }
\end{tabular}

\section{GENERAL DISCUSSION}

Brand extension is an important marketing strategy through which marketers are able to leverage their well-established brands in launching new product categories. Prior research has suggested that the key to success is consumers' perceived fit between extensions and their parent brand. Research to date has found that the fit is dependent upon the transferability of the parent brand's image and consumers' goal orientation. This research posits that the effectiveness of brand extension may also result from the fitness between the type of brand extension and the consumer's style of 
thinking. Specifically, analytic thinkers prefer benefit-similar to category-similar extensions. On the contrary, holistic thinkers prefer category-similar over benefit-similar extensions. Results from the experiment support this hypothesis.

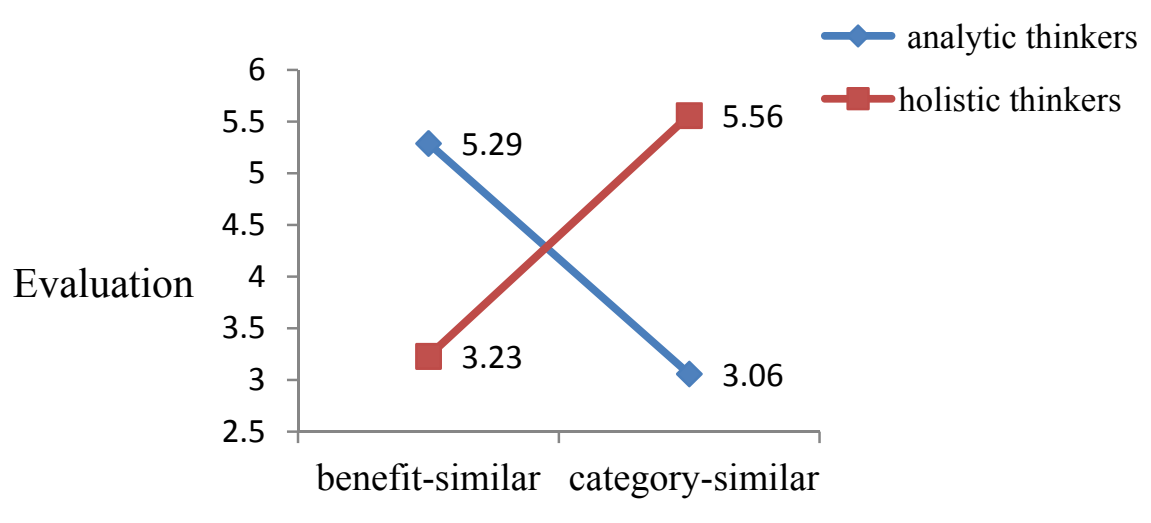

Brand Extension

Figure2 Effect of Style of Thinking and Brand Extension Types on Brand Evaluation

\section{THEORETICAL AND MANAGERIAL IMPLICATIONS}

\section{Theoretical Implications}

Past research has suggested that brand extension success is centered on consumers' perceived fit between the extension and the parent brand. A higher perceived fit leads to more favorable evaluations of the extension. As a consequence, the similarity between the parent brand and its extensions, which is a source of perceived fit, has a favorable effect by generalizing brand images to these extensions. Associations of similarity can be judged in a variety of ways, including product categories, features, usage situations, and target customers (Herr, Farquhar, \& Fazio, 1996; Keller, 1993). This research identifies two types of similarity associated with brand extensions: category similarity and benefit similarity. Results from an experimental design support the proposed hypotheses that the impact of brand extension type on consumer evaluations is moderated by the consumers' style of thinking. In particular, holistic thinkers favor category-similar brand extensions (vs. benefit-similar extension), whereas analytic thinkers favor benefit-similar extensions (vs. category-similar extensions).

Although the findings have implications for a number of research streams, they are most applicable to studies pertaining to the identification of boundary conditions for the perceived fit effect with regard to brand extensions. Prior research has generally suggested that the higher the perceived fit, the more favorable the consumer evaluation 
toward the extensions. However, this research has shown that the perceived fit effect may be moderated by people's styles of thinking. For instance, high perceived category similarity (benefit similarity) between the extension and the parent brand leads to more favorable extension evaluations for those people who embrace a holistic (analytic) thinking style. That is, perceived fit or similarity is in general very important for producing a positive brand extension effect, but its influence varies according to styles of thinking. Another contribution of this research lies in its finding that the perceived fit effect may differ among consumers from various cultures. The Western (Eastern) culture, which is characterized by analytic (holistic) thinking, is prone to react more positively to benefit-similar (category-similar) brand extensions.

\section{Managerial Implications}

Brand extension is a common practice that marketers use to introduce a new product carrying the parent brand name. Marketers can choose to launch an extension in a product class similar to the parent brand or an extension that offers similar core benefits. However, it is worth noting that the effectiveness of these two types of brand extension may vary according to consumers' styles of thinking. Results from this study have revealed that holistic thinkers tend to favor the category-similar extension, while analytic thinkers are inclined to favor the benefit-similar extension. Since most research to date has found that people from Western (Eastern) cultures are characterized by an analytic (holistic) thinking style, the best extension for Western (Eastern) culture is a benefit-similar (category-similar) brand extension. This finding is especially important for global companies that market their offerings in countries with different cultures.

\section{LIMITATIONS AND FUTURE RESEARCH DIRECTIONS}

There are some limitations to this study. First, all participants in this research are Chinese. Because people's styles of thinking are of a culture-dependent nature, the homogeneity of the sample may limit the external validity of findings from this study. Future research conducted with participants from different cultures, such as Westerners and Easterners, is encouraged. Second, participants' prior buying experiences with electric shavers, electric toothbrushes, and food processors used in this study are not considered. The possible impacts of consumers' experiences with relationships between brand extension types, thinking styles, and brand attitudes may be worthy of further investigation. 


\section{REFERENCES}

Ahluwalia, R. (2008). How far can a brand stretch? Understanding the role of self-construal. Journal of Marketing Research, 45(3), 337-350. http://dx.doi.org/10.1509/jmkr.45.3.337

Boush, D. M. \& Loken, B. (1991). A process-tracing study of brand extension evaluation. Journal of Marketing Research, 28(1), 16-28. http://dx.doi.org/10.2307/3172723

Campbell, M. C. \& Goodstein, R. C. (2001). The moderating effect of perceived risk on consumers' evaluations of product incongruity: Preference for the norm. Journal of Consumer Research, 28(3), 439-449. http://dx.doi.org/10.1086/323731

Chakravarti, D., MacInnis, D. J. \& Nakamoto, K. (1990). Product category perceptions, elaborative processing and brand name extension strategies. Advances in Consumer Research, 17(1), 910-916.

Chang, C. C., Lin, B. C., \& Chang, S. S. (2011). The relative advantages of benefit overlap versus category similarity in brand extension evaluation: The moderating role of self-regulatory focus. Marketing Letters, 22, 391-404. http://dx.doi.org/10.1007/s11002-010-9131-0

Chernev, A. (2004). Goal orientation and consumer preference for status quo. Journal of Consumer Research, 31(3), 557-655. http://dx.doi.org/10.1086/425090

Chiu, L. (1972). A cross-cultural comparison of cognitive styles in Chinese and American children. International Journal of Psychology, 7(4), 335-342. http://dx.doi.org/10.1080/00207597208246604

Choi, I., Nisbett, R. E., \& Norenzayan, A. (1999). Causal attribution across cultures: Variation and universality. Psychological Bulletin, 125(1), 47-63. http://dx.doi.org/10.1037/0033-2909.125.1.47

Choi, I., Koo, M., \& Choi, J. (2007). Individual differences in analytic versus holistic thinking. Personality and Social Psychology Bulletin, 33(5), 691-705. http://dx.doi.org/10.1177/0146167206298568

Dacin, P. A. \& Smith, D. C. (1994). The effect of brand portfolio characteristics on consumer evaluations of brand extensions. Journal of Marketing Research, 31(2), 229-242. http://dx.doi.org/10.2307/3152196

Han, J. \& Schmitt, B. (1997). The relative importance of product-category dynamics and corporate identity in brand extensions: A comparison of Hong Kong and U.S. consumers. Journal of International Marketing, 5 (1), 77-92.

Herr, P. M., Farquhar, P. H. \& Fazio, R. H. (1996). Impact of dominance and relatedness on brand extensions. Journal of Consumer Psychology, 5(2), 135-159. 
http://dx.doi.org/10.1207/s15327663jcp0502_03

Ji, L., Peng, K. \& Nisbett, R. E. (2000). Culture, control, and perception of relationships in the environment. Journal of Personality and Social Psychology, 78(5), 943-955. http://dx.doi.org/10.1037//0022-3514.78.5.943

John, D. R. (2004). Consumer response to brand extensions: Does culture matter? Advances in Consumer Research, 31, 216-222.

Keller, K. L. (1993). Conceptualizing, measuring, and managing customer-based brand equity. Journal of Marketing, 57(1), 1-22. http://dx.doi.org/10.2307/1252054

Keller, K. L. \& Aaker, D. A. (1992). The effects of sequential introduction of brand extensions, Journal of Marketing Research, 29(1), 35-50. http://dx.doi.org/10.2307/3172491

Liang, B. (2012). The effect of analytic and holistic thinking on consumers' attitudes' toward holistic or attribute advertising, AMA Summer Educators' Conference Proceedings, 23, p111.

Mandler, G. (1982). The structure of value: Accounting for taste. In M. S. Clark \& S. T. Fiske (Eds.) Affect and cognition: The 17th annual Carnegie symposium on cognition (pp. 3-36). Hillsdale, NJ: Erlbaum.

Mao, W. \& Oppewal, H. (2012). The attraction effect is more pronounced for consumers who rely on intuitive reasoning. Marketing Letters, 23(1), 339-351. http://dx.doi.org/10.1007/s11002-011-9157-y

Masuda, T. \& Nisbett, R. E. (2001). Attending holistically versus analytically: Comparing the context sensitivity of Japanese and Americans. Journal of Personality and Social Psychology, 81(5), 922-934. http://dx.doi.org/10.1037/0022-3514.81.5.922

Meyvis, T. \& Janiszewski, C. (2004). When are broader brands stronger brands? An accessibility perspective on the success of brand extensions. Journal of Consumer Research, 31(2), 346-357. http://dx.doi.org/10.1086/422113

Monga, A. B. \& John, D. R. (2007). Cultural differences in brand extension evaluation: The influence of analytic versus holistic thinking. Journal of Consumer Research, 33(4), 529-536. http://dx.doi.org/10.1086/510227

Monga, A. B. \& John, D. R. (2008). When does negative brand publicity hurt? The moderating influence of analytic versus holistic thinking. Journal of Consumer Psychology, 18(4) , 320-332. http://dx.doi.org/10.1016/j.jcps.2008.09.009

Monga, A. B. \& John, D. R. (2010). What makes brands elastic? The influence of brand concept and styles of thinking on brand extension evaluation. Journal of Marketing, 74(3), 80-92. http://dx.doi.org/10.1509/jmkg.74.3.80 
Nisbett, R. E. (1998). Essence and accident. In J. Cooper \& J. Darley (Eds.). Attribution, processes, person perception, and social interaction: The legacy of Ned Jones (pp.169-200), Washington, DC: American Psychological Association.

Nisbett, R. E., Peng, K., Choi, I., \& Norenzayan, A. (2001). Culture and systems of thought: holistic versus analytic cognition. Psychological Review, 108(2), 291-310. http://dx.doi.org/10.1037//0033-295X.108.2.291

Norenzayan, A., Smith, E. E., Kim, B. J., \& Nisbett, R. E. (2002). Cultural preferences for formal versus intuitive reasoning. Cognitive Science, 26(5), 653-684. http://dx.doi.org/10.1207/s15516709 $\operatorname{cog} 2605 \_4$

Peng, K. \& Nisbett, R. E. (1999). Culture, dialectics, and reasoning about contradiction. American Psychologist, $54 \quad$ (9), 741-754. http://dx.doi.org/10.1037//0003-066X.54.9.741

Yeo, J. \& Park, J. (2006). Effects of parent-extension similarity and self regulatory focus on evaluations of brand extensions. Journal of Consumer Psychology, 16(3), 272-282. http://dx.doi.org/10.1207/s15327663jcp1603_9

Zhou, R. \& Pham, M. T. (2004). Promotion and prevention across mental accounts: when financial products dictate consumers' investment goals. Journal of Consumer Research, 31(1), 125-135. http://dx.doi.org/10.1086/383429 
